\title{
STUDY OF SOCIAL MATURITY OF A PERSONALITY
}

\section{Yaroslav Haleta, Olena Habelko}

${ }^{I}$ Doctor of Sciences (Pedagogy), Associate Professor, Central Ukrainian State Pedagogical University named after V. Vynnychenko, Kropyvnytskyi, Ukraine, e-mail: yaroslavhaleta@ukr.net, ORCID: https://orcid.org/0000-0003-0484-529X

${ }^{2}$ Ph.D. (Pedagogy), Candidate of Pedagogical Sciences, Associate Professor, Central Ukrainian State Pedagogical University named after V. Vynnychenko, Kropyvnytskyi, Ukraine, e-mail: lena_gabelko@i.ua, ORCID: https://orcid.org/0000-0003-3769-3616

Abstract. The problem of the formation of a personality in modern conditions of growth of the role of information and communication technologies is becoming one of the most urgent in the field of pedagogical research. The volume of information, information resources, and relevant technologies makes a significant impact both on various aspects of public life and on the processes of the formation of a person's personality in particular. The article is devoted to the analysis of the definition of the relationship between the social maturity of the individual and the culture of the society. Specific features of personality formation in the information society have been determined. The research has shown that scientists connect the solution to the given problem with the formation of information culture of a person. The research reflects the development of understanding the essence of the category "social maturity", as well as outlines a number of concepts, understanding of the essence of which will allow to be detailed in relation to its content. It is proved that social maturity is conditioned by certain personality qualities that have an effective influence on selfregulation of behavior. Social maturity of the individual is a qualitative degree of his development in the conditions of a specific social environment that ensures creative involvement into various types of social and cultural situation and promotes his social growth. The study of the social maturity of the individual in pedagogical research is caused by the need to search for effective forms and methods of education in the interaction of self-education and the actions of the social environment. It has been justified that in the pedagogical sense, the content of social maturity reflects only what is actually formed in a person in the form of personality traits, and also that from the external transformed to the internal structure of the new formation of a personality is directly realized in his transforming activity aimed at improving the types of activities and relations, which form the personality.

Keywords: personality, socialization, communication, maturity, social maturity, information society.

JEL Classification: I0; I20

Formulas: 0; fig.: 0; tabl.: 0; bibl.: 10

Introduction. Over the last century, the world has witnessed tremendous changes in the lives of people and society, in the development of technology and culture. The main element that accompanies these changes are changes in human communication.

Most researchers of the role of personal computers and computer networks note that their spread leads to the formation of the information society. However, the introduction of information technology as a means of finding, collecting, storing, processing, providing, disseminating information in human life does not bring us closer to the information society, which was described by D. Bell, A. Turen, E. Tofflier, P. Draker, Z. Bzhezynskyi, J. Masuda and others. The information society has not been formed yet, although the main attributes are present. There is a lot of information in modern society, it plays a huge role, but in the triad of message - 
communication - interpretation, the process of transmitting is decisive. It is necessary to note the fact that the development of simulation technologies, not information technology has become a priority in recent years. As a result of increasing the RAM and speed of computers, as well as the creation of new software, there are not only qualitatively new forms of data transmission and processing, but first of all there is a growing similarity between working on a computer and managing real objects, as well as the similarity of online communications with communication in real space time. Computerization of everyday life introduces virtual reality as computer simulations of real things and actions. Such intensive use of virtual reality technologies in recent years has a social meaning - the replacement of social reality with computer simulations. This social aspect of the development of computer technology clearly prevails over the technical aspect.

Thus, the urgency of the problem of personality formation, in particular its social maturity, in terms of updating the information culture of society follows, on the one hand, from the ontological significance of information in life, on the other hand, from increasing the functional importance of information in human life has become a system-forming value.

Literature review. Various aspects of the problem of social maturity are reflected in the psychological concepts of socialization and individualization of personality by G.M. Andrieieva, I.S. Koka, B.D. Paryshna; social attitudes and values (V.M. Miasyshchev, S.H. Nadyrashvili, P.N. Shykhyrev, V.O. Yadov); development of problems of leadership and leadership E.M. Dubovska, R.S. Nemova, T.M. Niukoma, F. Fiedler; social conflicts (V.O. Sosnin); stability of behavior in extreme social conditions (O.O. Zhuravlyov, V.O. Khashchenko); in theoretical ideas about personal maturity in the domestic (O.G. Asmolov, B.S. Bratus, V.P. Zinchenko, V.S. Mukhina, V.A. Petrovsky, N.I. Sobolev, V.I. Slobodchikov ) and foreign psychology (A. Adler, A. Maslow, G. Allport, K. Rogers, W. Frankl, E. Fromm); in studies of the conditions of human development as a subject of cognition (G.V. Akopov, V.Y. Lyaudis, V.O. Yakunin); in the development of methods of active sociopsychological training (Y.M. Yemelianov, E.S. Kuzmin, L.O. Petrovska) and others. However, the place of social maturity as a factor in the formation of personality in the information society is not fully disclosed.

Aims. To show the dependence of determining the content of the maturity of the individual on the specific culture of society.

Methods. The main method used in the article is semantic analysis of the main problems to understand the subject area.

Results. The processes of communication and interaction have the specificity of manifestation in terms of increasing the role of information and communication technologies in human life, and this indicates the peculiarity of the formation of a personality.

The conditionality of a personality development by procedural and substantive characteristics of communication, in which the individual enters, the roles that the individual assumes, based on the role of certain personal characteristics, thereby consolidating them, is not limited to consideration of stages of ontogenesis to its 
maturity (or ontogenet adulthood). Further, depending on the participants of the communication, the role of the person in this communication, the resources and personal qualities he/she relies on, actualizing them in relation to other person, he/she continues to change. What significant relationships and situations of communication a person goes through, what subjective activity he realizes, in whose address this activity is directed (in relation to whom the personality manifests itself in its activity), what personal meaning is endowed with activity, and is "the way personality ", its formation and self-determination.

It is also important that information technology tools carry out almost instantaneous transmission of cultural values, as if compressing space and speeding up time. The information is transmitted in real time, creating the user's involvement in the course of modern history.

Passive consumption of information through computers, television, audio, radio and telephone increasingly displaces active forms of leisure, creativity, cognition, forms a rigidity of thinking, deprives people of direct communication with each other. Narrowing of personal space, alienation from wildlife causes an involuntary desire to simplify the picture of the world, fear of decision-making, fear of responsibility. Electronic communication is devoid of many aspects of the social context present in terms of personal contact. A person using a computer tends to speak more freely.

Telecommunication resources allow a person to be independent of time and space. In terms of connecting to extensive computer networks, they can communicate with people anywhere in the world; participate in group discussions, teleconferences.

It is natural that a change in people's thinking has an impact on their behavior, needs and ways of meeting them, overall way of life of individuals and society as a whole. This fact makes it socially significant to study the problems of socialization of the individual under the influence of computer technology. The interaction of man and computer becomes a social phenomenon and is not just human communication with technology, but an active process of human interaction with the information richness of human experience accumulated over the centuries.

In view of the above, we should note that human socialization in cyberspace, on the one hand, is a relatively innovative phenomenon, on the other hand, has long been a factual reality of our world, an integral part of socialization of modern personality, as well as the engine of scientific, technical, economic and the social progress of human society. Paying attention to Internet socialization, it is necessary to emphasize that the Internet environment itself is a new level of social network (there is a permanent increase in the number of users) interaction of modern people of almost different ages, at least from adolescents to the elderly, while socialization in cyberspace.

Discussion. Thus, in the modern era of information explosion and information revolution, humanity is forced for a limited time to adapt to the new conditions of their existence. This sharply highlights the need to discuss the very problem of human interaction with the information environment. 
According to L. Mumford, a man, above all, is an animal that creates its own mind, restrains itself and self-programs. Its own organism and social organization, in which this organism becomes more fully expressed is considered to be the primary source of all its activities. Until man has done something of himself, he cannot do much in the world around him [4]. .

The role of cultural activity in human development has not yet been studied in proportion to its importance in this process. This can be fully attributed to the role of information culture in human development as a biological and social being.

Relatively recently, the development of the society has been characterized as socio-cultural, but today it looks more like technocratic. The spiritual, intellectual potential of the society is increasingly identified with the information, causing changes in culture, language, lifestyle and even thinking. Information and awareness of the individual began to replace his knowledge, human ability to comprehend and solve problems.

It would be a simple utopia to ignore the development of technology and its effect on man and society as a whole, because it is a material means of human activity and, consequently, culture. You can agree with V. M. Rozin who claims that human activity has two components - acts of activity that are implemented on a rational basis, and cultural components that live by a different logic. Therefore, he concludes that most of the problems that arise in society today cannot be solved in a scientific and technical way [7].

J. Bodriiiar, who studied the problems of the information society, believed that modern culture is a culture of signs. But signs, instead of reflecting reality, simulate it. Modern society, according to Bodriiiar, is filled with signs. Every day, the media attack the consumer with a huge number of facts and their interpretations. Consciousness is divided due to the fact that he can not understand all this and distinguish their own desires from others [1]. Therefore, the task of analyzing the positive and negative aspects of the adaptation process is very important now.

The problem of adaptation of human society is carried out not so much by adaptive physiological abilities, but by building a supra-individual adaptive system culture.

As we know, the individual and society are two poles of social reality, where the individual is a specific historical phenomenon, and society forms its own type of personality.

D.I. Feldshtein sees the main meaning of human social development in the appropriation of the social essence of a man. The degree of mastery of a person's social experience of actions and relationships, self-awareness in society, self-vision in other people, willingness to act responsibly in the world is the result of social development.

Consideration of personal development in the conditions of informatization concerning social maturity seems to us perspective.

A common understanding of the concept of "maturity" is given in dictionaries. The dictionary of the Ukrainian language defines "maturity" as "the state of an organism that has reached full development; high degree of development, perfection, 
skills". And then "mature is someone who has reached a certain development; who has extensive experience, has achieved high skill, is fully formed; deeply thought out, created, carried out on the basis of extensive experience, skill, etc. " [8].

According to L.M. Kohan, concept of "maturity" can be applied in any complex system to characterize its individual elements and the system as a whole. This is the state of the elements and the whole system, in which this element is able to fully perform its functions, to implement in practice (functioning) its qualitative characteristics. That is, the maturity of the system as a whole means the full implementation of its system quality [3].

Of many definitions of a mature personality, in which the main manifestations of the properties are recorded, the interpretation of P.Ya. Halperin, who believes that the individual can be considered mature when freely and consciously chosen and set the goals of their actions (taking into account causal relationships, their moral sense), for the consequences of which the individual is responsible to nature, society and conscience [2, with. 91].

In the socio-psychological context, the concept of "maturity" is often interpreted as an achievement in the development of personality and individuality, which are characterized by a person's ability to "independence" in life, when he does not need those "supports" and "help" from others vital balance and would provide resistance to the difficulties of life (K.O. Abulkhanova-Slavska, G. M. Andrieieva, O.G. Asmolov, V.I. Slobodchikov, etc.).

In particular, G.S. Sukhobska $[9 ; 10]$ in a number of her works dwells on the characteristics of the most important attributes of individual psychological maturity, to which she attributes the following abilities:

- to independently predict their behavior in any life situation on the basis of developed skills to obtain the necessary information and analyze it in relation to the goals associated with the solution of specific and unusual situations in all spheres of life;

- to mobilize themselves to implement their own decision to act in spite of various circumstances and the internal socially unmotivated desire to stop it ("tired", "do not want", "difficult" and the like);

- to self-monitoring the progress of their own actions and their results (which implies the readiness of the person to "normal imaginary split" into "I am a performer" and "I am a controller");

- to the manifestation of evaluative reflection on the basis of formed selfawareness and objective unbiased assessment of their thoughts, actions, deeds;

- to an emotionally adequate reaction to various situations of one's behavior.

General philosophical understanding of this concept implies that it is a complex system with a special type of functioning and development. It is characterized by internal optimality. It is the optimality of functioning that provides not only the direction of development of the individual, the emergence and accumulation of its new strategic opportunities, but manifests itself as an indicator of its integrity, organization, which is an important factor in its further development. 
Summarizing the diversity of the content of the phenomenon "social maturity of the individual", V.V. Radul notes that: "the individual is the subject of human activity, which in its turn is aimed at transforming the surrounding reality" [5, p.2526]. Each person learns specific historical forms and ways of knowing the world and thus forms an individual, unique personality in the cultural sense, formed by their own life experience and way of knowing it [5, p. 26].

The analysis showed the dependence of determining the content of a person's maturity on a particular culture, "because a person is formed in a specific historical time and space, in the process of practical activities and education" [6, p. 41].

Conclusions. The article focuses on the impact of information on public life. The dependence of the content of personality maturity on a specific culture of society has been shown. Prospects for further research are due to the interaction of the phenomena of the information society and human personality.

Author contributions. The authors contributed equally.

Disclosure statement. The authors do not have any conflict of interest.

\section{References:}

1. Bodrijyar, ZH. V. (2000). Teni molchalivogo bol'shinstva, ili Konec social'nogo. [Shadows of silent majority, or End of social]. Ekaterinburg.

2. Gal'perin, P. YA. (1976). Vvedenie v psihologiyu. [Introduction to Psychology]. Moscow.

3. Kogan, L. N. (1984). Cel' i smysl zhizni cheloveka. [The purpose and meaning of human life]. Moscow.

4. Mamford, L. (1986). Tekhnika i priroda cheloveka. [Technology and nature of man]. Moscow.

5. Radul, V. V. (2017). Social'na zrilist' osobistosti. [Social maturity of the individual]. Kharkiv.

6. Rean, A. A. (2008). Social'naya pedagogicheskaya psihologiya. [Social pedagogical psychology]. Spb.

7. Rozin, V. M. (2006). Ponyatie i sovremennye koncepcii tekhniki. [Concept and modern concepts of technology]. Moscow.

8. Slovnik ukraïns'koï movi. V 10 tomah. T.3. (1972). [Dictionary of the Ukrainian language.]. Kyiv.

9. Suhobskaya, G. S. (2002). Ponyatie «zrelost' social'no-psihologicheskogo razvitiya cheloveka» v kontekste andragogiki. [The concept of «maturity of the socio-psychological development of man» in the context of andragogy]. Moscow.

10. Suhobskaya, G. S. (2007). Social'naya i social'no-psihologicheskaya zrelost': osnovy identifikacii lichnosti v obrazovatel'nom processe. [Social and socio-psychological maturity: the basis for identification of the individual in the educational process]. Moscow 